\title{
Psychosis in Indigenous populations of Cape York and the Torres Strait
}

\section{Ernest M Hunter \\ FRANZCP \\ Regional Psychiatrist Bruce D Gynther \\ Regional Psychiatrist}

Carrick J Anderson

Psychiatry Registrar

Leigh-ann L Onnis GradDipPH,

Research Assistant

Jeffrey R Nelson PhD,

Senior Principal Research Officer

Wayne Hall NHMRC Australia Fellow

Bernhard T Baune PhD, MD, FRANZCP. Professor and Chair of Psychiatry

Aaron R Groves FRANZCP,

Executive Director

1 Regional and Remote Mental Health Service Queensland Health, Cairns, QLD.

2 School of Indigenous Australian Studies, James Cook University, Cairns, QLD.

3 University of Queensland Centre for Clinical Research. Brisbane, QLD.

4 Discipline of Psychiatry, School of Medicine University of Adelaide Adelaide, SA.

5 Mental Health, Alcoho and Other Drugs Directorate, Queensland Health, Cairns, QLD. ernest_hunter@ health.qld.gov.au

MJA 2012; 196: 133-135 doi: 10.5694/mjall.10118

Editorial p 89 Clinical focus p 118 espite mental illness being a major contributor to the health gap for Aboriginal and Torres Strait Islander adults, ${ }^{1}$ reliable prevalence and severity data are limited. Although there has been work focusing on assessment ${ }^{2}$ and service delivery, ${ }^{3}$ research has been limited to a small case-control study ${ }^{4}$ and studies of subgroups at elevated risk. ${ }^{5,6}$ As a rough indicator, in the 2005-06 financial year, male and female Indigenous Australians were hospitalised for psychiatric disorders at 2.4 and 1.5 times the rate for non-Indigenous Australians, respectively. ${ }^{7}$ The admission rate ratios for male and female Indigenous Australians for schizophrenia and delusional disorders were 2.7 and 2.5, and for mental disorders due to psychoactive substances, 4.5 and $3.3,{ }^{7}$ respectively.

In this analysis, we aimed to describe and characterise treated psychotic disorders in the Indigenous population of Cape York and the Torres Strait Islands in Far North Queensland.

\section{Methods}

\section{Study location and population}

Cape York and the Torres Strait region cover $7.5 \%$ of Queensland, with a population estimate for 2009 of 24049 - $0.5 \%$ of Queensland's population. ${ }^{8}$ Extrapolating from 2006 ethnic breakdown data, ${ }^{9}$ the region's Indigenous population in 2009 was estimated at 15904 (39\% Aboriginal, 45\% Torres Strait Islander, and 16\% both Aboriginal and Torres Strait Islander), of whom 10217 were aged 15 years and older, and constitute the denominator for the calculation of prevalence rates in this study.

\section{Data collection}

In mid 2010, we collated data on all adult Indigenous patients in the region who where either symptomatic or in remission and receiving treatment for a psychotic disorder falling within the following International Classification of Diseases, 10th revi-

Abstract

Objective: To describe and characterise treated psychotic disorders in the Indigenous populations of Cape York and the Torres Strait.

Design: Cross-sectional analysis of patients with a psychotic disorder identified by treating psychiatrists.

Setting and participants: Indigenous patients aged $\geqslant 15$ years in Cape York and Torres Strait communities receiving treatment for a psychotic disorder over 3 months in 2010.

Main outcome measures: Prevalence of psychosis diagnoses, intellectual disability, and substance use comorbidities.

Results: 171 patients were included. The prevalence rate in this population was $1.68 \%$, higher for males $(2.60 \%)$ than females $(0.89 \%)$, and twice as high in the Aboriginal $(2.05 \%)$ than in the Torres Strait Islander (0.95\%) population. High rates of alcohol and cannabis use were found. Comorbid intellectual disability was common and more frequent among Aboriginal patients.

Conclusions: The burden of psychosis in the Indigenous population of Cape York and the Torres Strait is high. Further research is needed to understand the social determinants of these disorders and to design effective social and clinical measures to alleviate this burden.

sion groups: organic-related (F06); substance use-related (F10-19); schizophrenia-related (F20-22); acute and transient psychoses (F23); and mood disorder-related (F25, F30-33). Participants were patients of the Rural and Remote Area Mental Health Service (Queensland Health) and were assessed by one of two of the authors (EMH and BD G) who have been psychiatrists in this region for 18 and 10 years, respectively. These clinicians review all cases of psychosis in the region, and patients were identified through the service's clinical database.

All information included in this study is routinely collected. Permission to collate for review was obtained from the Queensland Health Data Custodian and was approved by the Cairns Base Hospital Human Research Ethics Committee.

Although extensive data were collated, those relevant to this article are demographics, diagnoses, and clinicians' judgements regarding whether alcohol and cannabis were significant to the onset or current psychiatric condition, and the presence of intellectual disability.

\section{Statistical methods}

Prevalence rates were calculated by sex, age and ethnicity. Because a small proportion of the sample identified as being both Aboriginal and Torres Strait Islander, prevalence rates by ethnicity were calculated in two ways. First, we removed data from participants who identified as being both Aboriginal and Torres Strait Islander from both the sample and population. Second, for a more conservative estimate, we collapsed the data from the "both" category into the Aboriginal or Torres Strait Islander categories at the sample and population levels using the proportions observed in the population.

This study is primarily descriptive, intending to highlight prevalence rates, between-group differences in prevalence rates, and a selection of within-sample associations that may provide clues as to why the rates are high. As such, univariate statistical analyses were used sparingly, and no attempt was made to explain the magnitude of the prevalence rates. The statistical significance of between-group differences was established using $\chi^{2}$ tests with $P=0.05$ (two-sided).

\section{Results}

Of the 171 patients included in the study, 124 were reviewed or assessed during routine clinical community visits over 3 months in 2010 (72.5\%). 


\begin{tabular}{|c|c|c|c|}
\hline & Sample, no. (\%) & Population, \% & Prevalence, \% \\
\hline \multicolumn{4}{|l|}{ Ethnicity } \\
\hline Aboriginal & $108(63.2 \%)$ & $38.5 \% ;^{\dagger} 46.1 \%^{\ddagger}$ & $3.23 \% ;^{\dagger} 2.05 \%^{\ddagger}$ \\
\hline Torres Strait Islander & $58(33.9 \%)$ & $45 \% ;^{\dagger} 53.9 \% \%^{\ddagger}$ & $1.50 \% ;^{\dagger} 0.95 \% \%^{\ddagger}$ \\
\hline \multicolumn{4}{|l|}{ Sex } \\
\hline Male & $124(72.5 \%)$ & $47.8 \%$ & $2.60 \%$ \\
\hline Female & $47(27.5 \%)$ & $52.2 \%$ & $0.89 \%$ \\
\hline \multicolumn{4}{|l|}{ Age group } \\
\hline 15-29 years & $54(31.6 \%)$ & $24.4 \%$ & $1.39 \%$ \\
\hline 30-39 years & $57(33.3 \%)$ & $14.3 \%$ & $2.51 \%$ \\
\hline$\geqslant 40$ years & 60 (35.1\%) & $25.1 \%$ & $1.51 \%$ \\
\hline
\end{tabular}

*All within-category comparisons are statistically significant at $P<0.005$ level, youngest - oldest not significant. † "Both Aboriginal and Torres Strait Islander" category removed from calculations. ₹ "Both Aboriginal and Torres Strait Islander" category collapsed.

\section{Prevalence of psychotic disorders by sex and ethnicity*}

\begin{tabular}{lccc} 
Sex & $\begin{array}{c}\text { Aboriginal } \\
(n=110)\end{array}$ & Torres Strait Islander $(n=61)$ & $\chi_{1}{ }_{1} ; P$ \\
\hline Male $(n=124)$ & $3.59 \%$ & $1.57 \%$ & $\chi_{1}^{2}=20.2 ; P<0.001$ \\
Female $(n=47)$ & $1.23 \%$ & $0.67 \%$ & $\chi^{2}{ }_{1}=2.53 ; \mathrm{ns}$ \\
$\chi_{1}^{2} ; P$ & $\chi_{1}{ }_{1}=26.5 ; P<0.001$ & $\chi_{1}^{2}{ }_{1}=9.03 ; P=0.003$ & \\
\hline
\end{tabular}

ns = not significant. * "Both Aboriginal and Torres Strait Islander" category collapsed.

Seventeen were discussed with staff but not seen $(9.9 \%)$. Of the other 30 $(17.5 \%)$, three were in forensic detention $(1.8 \%)$, six in prison $(3.5 \%)$, four in hospital $(2.3 \%)$, and five in other institutional care (psychiatric rehabilitation, nursing home, acquired brain injury unit or supported accommodation) $(2.9 \%)$. The remaining 12 included those who had recently moved or been lost to follow-up (7.0\%). Previously diagnosed patients in remission and not receiving treatment were excluded.

The 171 patients included in the study were aged between 17 and 68 years. Primary diagnoses were: schizophrenia-related $(106 ; 62.0 \%)$, substance use-related $(39 ; 22.8 \%)$, mood disorder-related $(14 ; 8.2 \%)$, organicrelated $(6 ; 4 \%)$ and acute and transient psychoses $(6 ; 3.5 \%)$. The overall treated point prevalence for psychotic disorders for Indigenous residents of this region aged 15 years and older was $1.68 \%$.

In our sample, some patients identified as being of both Aboriginal and Torres Strait Islander descent $(3 \% \mathrm{v}$ $16 \%$ for the region). Prevalence rates by ethnicity with the "both" category removed and proportionally collapsed are shown in Box 1.
Sex by ethnicity stratified prevalence rates using the collapsed approach are shown in Box 2. Box 3 provides information about the patients' histories of hospitalisation (previous 12 months) and incarceration (lifetime), and whether they received depot medication. Box 3 also includes clinical judgements about compliance, whether alcohol or cannabis was currently used at clinically significant levels, and whether their use contributed to the onset of the psychotic disorders.

The prevalence of intellectual disability in the sample and the magnitude of their ethnicity-related differences presented in Box 3 were such that it was thought necessary to conduct further analyses on the 46 patients who were identified as having an intellectual disability. The results of these analyses show that the difference in proportions of Aboriginal and Torres Strait Islander patients identified with an intellectual disability was statistically significant (Box 4). A statistically significant difference was also revealed when this analysis was replicated with male patients only; but not with female patients only. There were no other statistically significant differences in intellectual disability between males and females.

\section{Discussion}

The treated prevalence rate for psychotic disorders in this Indigenous population is high, particularly among males and people of Aboriginal descent. Unfortunately, there is a dearth of articles that provide prevalence rates of psychotic disorders in the Australian context. Two of the more contemporary articles claim prevalence rates of about one-third of that calculated in this study. A study conducted at four urban centres, one each situated in Queensland (period prevalence rate, $0.42 \%)$, Victoria (0.59\%), Western Australia (0.69\%) and the Australian Capital Territory $(0.39 \%)$, found a period prevalence rate ( 1 month) for psychotic disorders of $0.47 \% .{ }^{10}$ A systematic review of 118 Australian and international studies found a period prevalence rate (1 to 12 months) for schizophrenia only of $0.55 \%$, and a prevalence rate of $0.43 \%$ in rural centres. ${ }^{11}$ Acknowledging the limitations of comparison with these

\section{Proportions of sample that are affected by selected attributes at the sample level and stratified by ethnicity and sex}

\begin{tabular}{|c|c|c|c|c|c|}
\hline & \multirow[b]{2}{*}{ Sample } & \multicolumn{2}{|c|}{ Ethnicity } & \multicolumn{2}{|c|}{ Sex } \\
\hline & & Aboriginal & Torres Strait Islander & Male & Female \\
\hline Alcohol: role in onset of disorder & $48.8 \%$ & $50.9 \%$ & $45.1 \%$ & $55.2 \%$ & $32.6 \%$ \\
\hline Alcohol: current clinical impact & $18.7 \%$ & $15.7 \%$ & $22.4 \%$ & $22.6 \%$ & $8.5 \%$ \\
\hline Cannabis: role in onset of disorder & $54.0 \%$ & $50.5 \%$ & $58.8 \%$ & $60.7 \%$ & $37.0 \%$ \\
\hline Cannabis: current clinical impact & $32.2 \%$ & $31.5 \%$ & $32.8 \%$ & $37.9 \%$ & $17.0 \%$ \\
\hline Hospitalisation (previous 12 months) & $32.7 \%$ & $34.3 \%$ & $29.3 \%$ & $29.8 \%$ & $40.0 \%$ \\
\hline Significant compliance problems & $42.0 \%$ & $42.6 \%$ & $39.3 \%$ & $45.8 \%$ & $29.5 \%$ \\
\hline Medication: depot administration & $59.6 \%$ & $69.4 \%$ & $41.4 \%$ & $62.8 \%$ & $51.1 \%$ \\
\hline Incarceration (lifetime) & $31.8 \%$ & $43.9 \%$ & $10.3 \%$ & $42.5 \%$ & $4.4 \%$ \\
\hline Comorbid intellectual disability & $26.9 \%$ & $38.9 \%$ & $6.9 \%$ & $29.0 \%$ & $21.3 \%$ \\
\hline
\end{tabular}




\begin{tabular}{|c|c|c|c|c|}
\hline \multicolumn{5}{|c|}{4 Intellectual disability, stratified by ethnicity and sex } \\
\hline \multirow[b]{2}{*}{ Sex } & & \multicolumn{2}{|c|}{ Ethnicity } & \multirow[b]{2}{*}{$\chi_{1}^{2} ; P$} \\
\hline & & Aboriginal & $\begin{array}{l}\text { Torres Strait } \\
\text { Islander }\end{array}$ & \\
\hline & & $n=42$ & $n=4$ & $\chi_{1}^{2}=17.72 ; P<0.001$ \\
\hline Male & $n=36$ & 34 & 2 & $\chi_{1}^{2}=16.6 ; P<0.001$ \\
\hline Female & $n=10$ & 8 & 2 & $\chi_{1}^{2}<1.0 ; \mathrm{ns}$ \\
\hline$\chi_{1}^{2} ; P$ & $\chi_{1}^{2}<1 ; \mathrm{ns}$ & $\chi^{2}=1.16 ; \mathrm{ns}$ & $\chi_{1}^{2}<1 ;$ ns & \\
\hline
\end{tabular}

studies, the elevated prevalence rates in the Indigenous populations described here are stark.

Alcohol and cannabis use appear common in this clinical population, and have been shown elsewhere to have psychiatric implications for Indigenous populations. Research in a remote WA Aboriginal population demonstrated that heavy alcohol use was associated with psychotic symptoms. ${ }^{12}$ However, comparison to this survey's findings may be complicated by differences between Cape York and the Torres Strait, including recent legislative restrictions on alcohol in Cape York. Although this would not have been relevant to the onset of psychosis (which preceded the restrictions for most patients), it has reduced quantities available since, and thus affected the impact on current clinical status. Widespread cannabis use is relatively recent, and the results are consistent with those in remote Northern Territory communities: cannabis use was more common among males (70\%) than females (20\%) (with $90 \%$ of users using heavily ${ }^{13}$ ), and was associated with psychotic ${ }^{5}$ and depressive symptoms. ${ }^{14}$

Nationally, $7.7 \%$ of Aboriginal and Torres Strait Islander people over 15 years of age have an intellectual disability, $^{15}$ and roughly $57 \%$ of Australians with intellectual disability develop a psychiatric disorder. ${ }^{16}$ The prevalence of intellectual disability in our sample was $26.9 \%$. This rate is substantially higher than that found in a WA study, which reported a prevalence of intellectual disability in a psychiatric sample of $1.8 \%{ }^{17}$ A review of admissions to the Cairns Base Hospital Acute Mental Health Ward found "cognitive difficulties" noted in the charts of $22 \%$ of Indigenous admissions in the 2004-05 financial year. ${ }^{18}$ Our study also showed a substantial difference between the rates of intellectual disability in the
Aboriginal (38.9\%) and Torres Strait Islander (6.9\%) patients. Evidence supporting acquired rather than genetic explanations for these differences have been explored elsewhere. ${ }^{19}$

Our study revealed several important findings, but is constrained by some methodological limitations. The most obvious of these is the reliance on clinical judgements, the potential for interrater reliability confounds, and potential effects of culturally informed biases (including potential for misdiagnosis among Indigenous patients with autism and intellectual disability ${ }^{20}$ ). However, there is evidence of good agreement between skilled clinicians for the diagnosis of psychosis among patients with intellectual disability, ${ }^{21}$ and in our study, all judgements were made by psychiatrists with shared responsibility for patients for many years. Although this does not establish validity or reliability, it makes it more likely that case ascertainment and interrater reliability are high, and as accurate as can be collected using applied clinical methods.

This study has corroborated clinical impressions of a high burden of psychosis in the Indigenous populations of Cape York and the Torres Strait, particularly male Aboriginal Australians. Our finding is supported by hospitalisation data showing that psychotic disorders are common and increasing in the Indigenous population of Far North Queensland. ${ }^{8}$ These disorders are associated with substance misuse and a surprisingly high rate of intellectual disability. The findings indicate an urgent need for further research in this region, to extend this research to other Indigenous populations, to identify causal and perpetuating factors, and to develop effective social and clinical measures to alleviate this burden.

Competing interests: No relevant disclosures.

Received 11 Feb 2011, accepted 14 Nov 2011.

1 Vos T, Barker B, Begg S, et al. Burden of disease and injury in Aboriginal and Torres Strait Islander peoples: the Indigenous health gap. Int J Epidemiol 2009; 38: 470-477.

2 Goulash A, Saunders J, White P, Nolan T. "Tell the story." Barriers to effective communication in mental health assessments for Aboriginal and Torres Strait Islander Peoples. The development of culturally appropriate assessments for Aboriginal and Torres Strait Islander mental health consumers. Brisbane: Queensland Centre for Schizophrenia Research, 1999. http://www.qcsr. uq.edu.au/atsi (accessed Dec 2011).
3 Nagel T, Robinson G, Trauer T, Condon J. An approach to treating depressive and psychotic illness in Indigenous communities. Aust J Prim Health 2008; 14: 17-24.

4 Mowry BJ, Lennon DP, De Felice CN. Diagnosis of schizophrenia in a matched sample of Australian Aborigines. Acta Psychiatrica Scandinavica 1994; 90: 337-341.

5 Clough AR, Lee KS, Cairney S, et al. Changes in cannabis use and its consequences over 3 years in a remote indigenous population in northern Australia. Addiction 2006; 101: 696-705.

6 Heffernan E, Andersen K, Kinner S. The insidious problem inside: mental health problems of Aboriginal and Torres Strait Islander people in custody. Australas Psychiatry 2009; 17: S41-S46.

7 Pink B, Allbon P. The health and welfare of Australia's Aboriginal and Torres Strait Islander people 2008. Canberra: Australian Institute of Health and Welfare and the Australian Bureau of Statistics, 2008.

8 Office of Economic and Statistical Research, Queensland Government. Queensland Regional Profiles. Brisbane: OESR, 2010. http://statistics. oesr.qld.gov.au/qld-regional-profiles (accessed Dec 2011).

9 Australian Bureau of Statistics. Census of population and housing 2006. Canberra: Australian Bureau of Statistics, 2007.

10 Jablensky A, McGrath J, Herrman H, et al. Psychotic disorders in urban areas: an overview of the Study on Low Prevalence Disorders. Aust N Z J Psychiatry 2000; 34: 221-236.

11 Saha S, Chant D, Welham J, McGrath J. A systematic review of the prevalence of schizophrenia. PLoS Med 2005; 2 (5): ell1.

12 HunterE, Hall W, Spargo R. Patterns and correlates of alcohol consumption in a remote Aboriginal population. Monograph No. 12. Sydney: National Drug and Alcohol Research Centre, 1991.

13 Lee KS, Conigrave KM, Patton G, Clough AR. Cannabis use in remote Indigenous communities in Australia: endemic yet neglected [editorial]. Med J Aust 2009; 190: 228-229.

14 Lee KS, Clough AR, Jaragbe MJ, et al. Heavy cannabis use and depressive symptoms in three Aboriginal communities in Arnhem Land, Northern Territory. Med J Aust 2008; 188: 605-608.

15 Australian Bureau of Statistics; Australian Institute of Health and Welfare. The health and welfare of Australia's Aboriginal and Torres Strait Islander peoples 2008. Canberra: AlHW, 2008. (AlHW Cat. No. IHW 21.)

16 Australian Institute of Health and Welfare. Disability in Australia: intellectual disability [media release]. Canberra: AlHW, 2008. (AlHW Cat. No. AUS 110.)

17 Morgan VA, Leonard H, Bourke J, Jablensky A. Intellectual disability co-occurring with schizophrenia and other psychiatric illness: population-based study. Br J Psychiatry 2008; 193: 364-372.

18 Australian Integrated Mental Health Initiative (AIMhi), Indigenous Stream, Far North Queensland. Chart analysis of clinical pathways and possible length of stay indicators at the mental health unit, Cairns Base Hospital. Cairns: North Queensland Health Equalities Promotion Unit, School of Medicine, University of Queensland, 2007.

19 Hunter E, Gynther B, Anderson C, et al. Psychosis and its correlates in a remote Indigenous population. Australas Psychiatry 2011; 19: 434-438.

20 Roy M, Balaratnasingam S. Missed diagnosis of autism in an Australian Indigenous psychiatric population. Australas Psychiatry 2010; 18: 534537.

21 Einfeld S, Tonge B, Chapman L, et al. Inter-rater reliability of the diagnoses of psychosis and depression in individuals with intellectual disabilities. J Appl Res Intellect Disabil 2007; 20: 384-390. 